\title{
Penerapan Algoritma Apriori untuk Prediksi Kebutuhan Suku Cadang Mobil
}

\author{
Agung Adi Firdaus" ${ }^{\# 1}$, Nur Iksan², Devy Nur Sadiah" ${ }^{\# 3}$, Linda Sagita ${ }^{\# 4}$, Dwiki Setiawan ${ }^{\# 5}$ \\ ${ }^{\#}$ Pendidikan Teknik Informatika dan Komputer, Universitas Negeri Semarang \\ Sekaran, Kec. Gunungpati, Kota Semarang, Jawa Tengah 50229 \\ 1agungfirdaus119estudents.unnes.ac.id \\ 2nur.iksan@mail.unnes.ac.id \\ ${ }^{3}$ devynursadiah10@gmail.com \\ ${ }^{4}$ lindasagita620@gmail.com \\ ${ }^{5}$ dwikisetiawan2@gmail.com
}

\begin{abstract}
Abstrak
Dalam pangadaan suku cadang untuk proses produksi mobil, dibutuhkan informasi atau pengetahuan terkait suku cadang mobil yang dibutuhkan agar proses dan hasil produksi perusahaan efektif dan efisien. Tujuan penelitian ini adalah menerapkan algoritma apriori untuk prediksi suku cadang mobil yang sering muncul. Subjek penelitian yang digunakan adalah data produksi mobil BMW PT Gaya Motor. Model penelitian yang dilakukan adalah market basket analysis. Tahapan penelitian yang dilakukan meliputi: (1) Pengumpulan Data; (2) Data Training; (3) Pembentukan Association Rule, (4) Uji Lift Ratio, dan (5) Penarikan Kesimpulan. Hasil penelitian yang didapatkan yaitu Tipe mobil BMW yang paling banyak diproduksi tahun 2018 adalah BMW 320 dan BMW 7 Series. Sehingga perusahaan dapat menggunakan hasil ini untuk menentukan strategi terkait pengadaan suku cadang pada tipe mobil tersebut. Berdasarkan Uji Lift Ratio yang telah dilakukan, terdapat dua rule yang sangat kuat dan valid untuk digunakan dalam prediksi suku cadang mobil BMW yaitu BMW 320 dan BMW 7 SERIES.
\end{abstract}

Kata kunci: Prediksi_Suku Cadang_Apriori

\section{Application of Apriori Algorithm for Prediction of Spare Parts Needs}

\begin{abstract}
In spare parts for the automotive production process, information or knowledge related to spare parts is required to process and produce efficient and efficient companies. The purpose of this research is to apply the apriori algorithm to predict the spare parts needs of cars that often appear. The research subject used is BMW PT Motor Style car production data. The research model used is market basket analysis. The step of research carried out includes (1) Data Collection; (2) Data Training; (3) Association Rule formation, (4) Lift Ratio test, and (5) Conclusions. The results of this research are the BMW Car Type that was mostly produced in 2018 are BMW 320 and BMW 7 Series. So the company can use this to determine a strategy related to the backup generator on the related car type. Based on the Lift Ratio Test that has been conducted, there are two very strong and valid rules to be used in predicting the BMW car spare parts these are BMW 320 and BMW 7 SERIES.
\end{abstract}

Keywords: Prediction_Spare Parts_Apriori

\section{Pendahuluan}

Seiring perkembangan zaman yang mengharuskan mobilitas tinggi, kebutuhan alat transportasi untuk kegiatan sehari-hari juga semakin meningkat. Hal ini memberikan peluang bagi perusahaan otomotif. Bagi suatu perusahaan, hal ini merupakan peluang untuk menguasai pasar pada bidang transportasi, salah satunya adalah mobil. Sehingga diperlukan cara yang tepat untuk meningkatkan produksi mobil yang berkualitas. Dalam pangadaan suku cadang guna proses produksi, dibutuhkan informasi atau pengetahuan terkait produksi mobil. Sehingga pembelian dan persediaan suku cadang sesuai dengan informasi produksi. Salah satu solusi kepada pemilik perusahaan adalah menggunakan data mining untuk mendapatkan pengetahuan terkait suku cadang yang berkaitan guna pengambilan keputusan dalam produksi mobil di waktu yang akan datang.

Menurut Larose, Data mining sendiri merupakan sebuah proses ekstrasi informasi untuk menemukan pola (pattern recognition) yang penting pada tumpukan data 
dalam database sehingga menjadi pengetahuan (knowledge discovery). Fungsi-fungsi dalam data mining antara lain fungsi deskripsi, fungsi estimasi, fungsi prediksi, fungsi klasifikasi, fungsi clustering dan fungsi asosiasi [1].

Salah satu fungsi data mining yang sangat bermanfaat dalam kegiatan produksi adalah prediksi. Fungsi prediksi merupakan proses untuk menemukan pola dari data dengan menggunakan beberapa variabel untuk memprediksikan variabel lain yang tidak diketahui jenis atau nilainya [2]. Melalui prediksi maka, pengambilan berbagai keputusan mempunyai dasar yang jelas dan terbukti menguntungkan dalam berbagai kegiatan ekonomi seperti penggunaan listrik di perumahan sampai skala industri [3] [4]. Oleh sebab itu industri mobil juga memerlukan penambangan data agar pengambilan keputusan lebih maksimal.

Salah satu algoritma yang seing digunakan adalah apriori. Berdasarkan penelitian-penelitian sebelumnya, penggunaan algoritma apriori dipilih karena algoritma ini efektif dan efisien dalam menentuka pola asosiasi suatu item. Selain itu algoritma ini juga mudah untuk diterapkan dan tidak membutuhkan waktu lama dalam prosesnya. Jenis penelitian yang digunakan dalam penelitian ini adalah penelitian eksperimen. Penelitian ini digunakan dengan menerapkan data mining berdasarkan asosiasi dengan menggunakan algoritma apriori, untuk memudahkan perusahaan atau analis dalam mengetahui pola produksi perusahaan.

Ada beberapa penelitian terkait dengan algoritma apriori dan implementasinya dalam berbagai bidang. Penelitian pertama dilakukan oleh Ristianingrum dan Sulastri (2017) dengan judul penelitian "Implementasi Data Mining Menggunakan Algoritma Apriori". Algoritma apriori dalam penelitian tersebut membantu dalam menentukan produk suku cadang yang dibeli berdasarkan pola transaksi konsumen yang dapat diketahui dari informasi dan jasa yang muncul [7]. Agoritma apriori untuk penentuan suku cadang juga dilakukan oleh Saputra dkk (2016). Dalam penelitian tersebut, data-data penjualan yang ada diolah dengan menggunakan algoritma apriori, yang menghasilkan produk suku cadang apa saja yang dibeli oleh konsumen khususnya ban luar dan oli mesin. Pihak Delta Motor dapat memperbanyak stok produk oli mesin dan ban luar [8]. Penelitian menggunakan algoritma apriori yang menjadi referensi lain diantaranya: oleh Prabawanti (2018) [9], Sholik dan Salam (2018) [10] dan juga dilakukan oleh Aditya dkk (2016) [11]. Oleh karena efektif dan efisiennya algoritma ini, penerapan juga perlu diterapkan ke PT. Gaya Motor yang belum mengaplikasikan algoritma ini.

Banyak sekali jenis mobil yang beredar saat ini. Salah satu jenis mobil dengan populasi tinggi dan terkenal di Indonesia adalah BMW. Produsen manufaktur otomotif BMW merupakan perusahaan induk dari Rolls-Royce Motor [5]. Objek penelitian ini adalah data produksi mobil BMW di PT Gaya Motor. PT. Gaya Motor berada di Jalan Gaya Motor Raya No. 3 Sunter II, Tanjung Priok Jakarta Utara. [6]. Dalam pengambilan keputusan terkait prediksi suku cadang untuk produksi, PT Gaya motor belum menerapkan data mining khususnya algoritma apriori. penggunaan algoritma apriori merupakan hal sangat dibutuhkan untuk pengambilan keputusan dalam membeli suku cadang apa saja yang akan dibutuhkan dan jumlahnya sesuai jenis mobil yang diproduksi .

Algoritma apriori merupakan salah satu teknik asosiasi dalam data mining. Algoritma apriori dapat membantu dalam memberikan informasi rekomendasi penyetokan barang dan mempermudah penataan serta penempatan suku cadang untuk proses produksi mobil pada PT Gaya Motor. Rumusan masalah dalam penelitian ini adalah Bagaimana Penerapan Algoritma Apriori Prediksi Suku Cadang Mobil BMW di PT Gaya Motor Jakarta Utara.

\section{Metodologi Penelitian}

Metode penelitian yang dilakukan adalah model Association atau Market Basket Analysis. Jenis data yang digunakan dalam penelitian ini adalah data sekunder yang diperoleh dari website resmi perusahaan. Penelitian ini dilakukan dalam beberapa tahapan, berikut langkahlangkah pengerjaan dalam melakukan penelitian. Langkah-langkah atau tahap yang dilakukan untuk mendapatkan aturan asosiasi pada data produksi mobil di PT Gaya Motor Jakarta Utara yaitu: (1) Pengumpulan Data; (2) Data Training; (3) Pembentukan Association Rule, (4) Uji Lift Ratio, dan (5) Penarikan Kesimpulan. Lebih lengkapnya tahapan penelitian disajikan pada flowchart berikut ini.

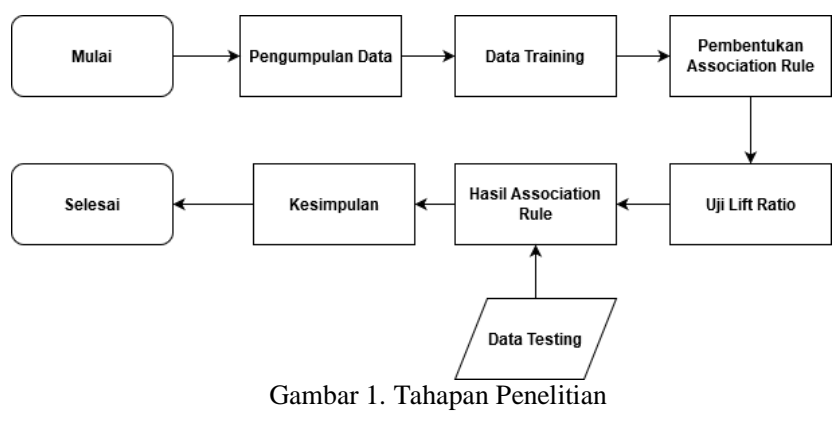

\section{A. Pengumpulan Data}

PT. Gaya Motor tepatnya berada di Jalan Gaya Motor Raya No. 3 Sunter II, Tanjung Priok Jakarta Utara. Pada mulanya PT. Gaya Motor berkedudukan di jalan Sulawesi Ujung No. 22 Tanjung Priok (di pelabuhan Tanjung priok). Data yang digunakan dalam penelitian ini adalah data sekunder melalui dokumentasi yaitu Data Produksi Mobil PT. Gaya Motor pada bulan Januari-Desember 2018 [6] [12].

\section{B. Data Training}

Pada tahap ini dilakukan pemilihan data yang sesuai dan pembuatan tabel data agar mudah dalam menerapkan algoritma apriori. Data-data yang digunakan dipilih dan dianalisis. Sedangkan transformasi data dilakukan dengan cara merubah bentuk data produksi ke dalam tabel. Setelah data siap diproses, selanjutnya adalah penerapan algoritma apriori. 


\section{Pembentukan Association Rule}

Penerapan algoritma apriori melalui dua proses dan tolok ukur, yaitu support dan confidence. Support (nilai penunjang) adalah persentase kombinasi item tersebut dalam database, sedangkan confidence (nilai kepastian) adalah kuatnya hubungan antara-item dalam aturan asosiasi [13]. Dalam pembentukan pola produksi oleh algoritma apriori ada dua tahapan. Tahapan pertama adalah mencari frequent itemset himpunan item yang memenuhi nilai minimum support. Lalu tahap kedua adalah membentuk pola asosiasi dari frequent itemset yang telah didapat dengan menggunakan nilai confidence [14]. Setelah kedua pola dilakukan, maka hasil dianalisis dan dijabarkan untuk mencari kesimpulan penelitian.

\section{Uji Lift Ratio}

Uji Lift Ratio adalah suatu metode yang digunakan untuk mengukur kekuatan asosiasi yang telah dibentuk. Lift Ratio dapat digunakan sebagai penentu kekuatan dan validitas pola asosiasi. Berikut ini adalah rumus Lift Ratio [13].

Lift Ratio $=\frac{\text { Confidence }(A, B)}{\text { Benchmark Confidence }(A, B)}$

berikut.

Benchmark Confidence dihitung dengan rumus

Keterangan :

$$
\text { Benchmark Confidence }=\frac{N c}{N}
$$

$\mathrm{Nc}=$ Jumlah transaksi dengan item yang menjadi consequent

$\mathrm{N}=$ Jumlah trasaksi basis data

\section{E. Penarikan Kesimpulan}

Dalam pembentukan pola asosiasi oleh algoritma apriori ada dua tahapan yaitu mencari frequent itemset membentuk pola asosiasi. Setelah kedua pola dilakukan, maka hasil dianalisis dan dijabarkan untuk mencari kesimpulan penelitian.

\section{HASIL DAN PEMBAHASAN}

Data yang diperoleh diolah menjadi dataset yang siap digunakan. Data yang digunakan adalah data produksi mobil BMW dengan beberapa tipe selama tahun 2018. Berikut ini adalah daftar tipe mobil BMW yang akan dianalisis, dapat dilihat pada Tabel I.

TABEL I

TIPE MOBIL BMW

\begin{tabular}{|l|l|l|}
\hline No & Tipe & Jenis \\
\hline 1. & BMW 320 & Mobil \\
\hline 2. & BMW 328/330 & Mobil \\
\hline 3. & BMW 520 & Mobil \\
\hline 4. & BMW 528 & Mobil \\
\hline 5. & BMW 7 SERIES & Mobil \\
\hline
\end{tabular}

Proses pertama adalah menentukan tabel itemset pada tiap transaksi. Item mobil dilambangkan dengan huruf satu sampai dengan lima. Satu untuk tipe BMW 320, dua untuk tipe BMW 328 dan seterusnya sebagaimana terdapat pada tabel 1. Data transaksi dibuat menjadi per bulan mulai Januari-Desember dan dilambangkan dengan angka 1 untuk bulan Januari, angka 2 untuk bulan Februari dan seterusnya. Berikut ini adalah itemset yang telah dibuat dapat dilihat pada Tabel II.

TABEL II

ITEMSET TABEL

\begin{tabular}{|l|l|}
\hline \multicolumn{1}{|c|}{ No } & \multicolumn{1}{|c|}{ Itemset } \\
\hline 1. & $1,5,4$ \\
\hline 2. & $5,1,2$ \\
\hline 3. & $4,5,3$ \\
\hline 4. & $4,2,1$ \\
\hline 5. & $1,4,5$ \\
\hline 6. & $1,5,3$ \\
\hline 7. & $1,2,5$ \\
\hline 8. & $1,2,3$ \\
\hline 9. & $3,4,2$ \\
\hline 10. & $1,4,3$ \\
\hline 11. & $4,1,5$ \\
\hline 12. & $3,2,4$ \\
\hline
\end{tabular}

\section{A. Penerapan Algoritama Apriori}

Penerapan algoritma apriori dilakukan dengan tahapan sebagai berikut.

1) Pembentukan 1 Itemset: minimal yang ditentukan adalah 30\% (Golden Rule). Berikut ini adalah pembentukan 1 itemset dengan menggunakan rumus di bawah ini [15].

$$
\frac{\sum \text { transaksiMengandungA }}{\sum \text { transaksi }} \times 100 \%
$$

Tabel III merupakan hasil pembentukan 1 itemset. TABEL III PEMBENTUKAN 1 ITEMSET

\begin{tabular}{|l|l|l|}
\hline No & Tipe & Support \\
\hline 1. & 1 & $75 \%$ \\
\hline 2. & 2 & $50 \%$ \\
\hline 3. & 3 & $50 \%$ \\
\hline 4. & 4 & $66,67 \%$ \\
\hline 5. & 5 & $58,33 \%$ \\
\hline
\end{tabular}

2) Pembentukan 2 Itemset: Proses pembentukan 2 itemset dengan minimum support $30 \%$ dilakukan dengan menggunakan rumus sebagai berikut [15].

$$
\frac{\sum \text { transaksiYangMengandingAdanB }}{\sum \text { transaksi }} \times 100 \%
$$

Hasil pembentukan 2 itemset ditunjukkan pada Tabel IV. 
TABEL IV

PEMBENTUKAN 2 ITEMSET

\begin{tabular}{|l|l|l|}
\hline No & Tipe & Support \\
\hline 1. & 1,2 & $\mathbf{3 3 , 3 3 \%}$ \\
\hline 2. & 1,3 & $25 \%$ \\
\hline 3. & 1,4 & $\mathbf{4 1 , 6 7 \%}$ \\
\hline 4. & 1,5 & $50 \%$ \\
\hline 5. & 2,5 & $16,67 \%$ \\
\hline 6. & 2,4 & $25 \%$ \\
\hline 7. & 2,3 & $20 \%$ \\
\hline 8. & 3,4 & $\mathbf{3 3 , 3 3 \%}$ \\
\hline 9. & 3,5 & $16,67 \%$ \\
\hline 10. & 5,4 & $\mathbf{3 3 , 3 3 \%}$ \\
\hline & & \\
\hline
\end{tabular}

Dari pembentukan 2 itemset dengan minimum support $30 \%$ pada Tabel V, didapatkan beberapa kombinasi yang memenuhi minimum support yaitu:

TABEL V

KOMBINASI YANG MEMENUHI MINIMUM SUPPORT

\begin{tabular}{|l|l|l|}
\hline No & Tipe & Support \\
\hline 1. & 1,2 & $33,33 \%$ \\
\hline 2. & 1,4 & $41,67 \%$ \\
\hline 3. & 3,4 & $33,33 \%$ \\
\hline 4. & 5,4 & $33,33 \%$ \\
\hline
\end{tabular}

3) Pembentukan 3 Itemset: Proses pembentukan 3 itemset dengan minimum support $30 \%$ dilakukan dengan menggunakan rumus sebagai berikut [15].

$$
\frac{\sum \text { transaksiYangMengandingA,BdanC }}{\sum \text { transaksi }} \times 100 \%
$$

Tabel VI merupakan hasil pembentukan 3 itemset.

TABEL VI

PEMBENTUKAN 3 ITEMSET

\begin{tabular}{|l|l|l|}
\hline No & Tipe & Support \\
\hline 1. & $1,5,3$ & $8,33 \%$ \\
\hline 2. & $1,5,2$ & $16,67 \%$ \\
\hline 3. & $1,4,5$ & $16,67 \%$ \\
\hline 4. & $2,1,3$ & $8,33 \%$ \\
\hline 5. & $2,3,4$ & $16,67 \%$ \\
\hline 6. & $2,3,5$ & $0 \%$ \\
\hline 7. & $3,4,5$ & $8,33 \%$ \\
\hline
\end{tabular}

Karena pada 3 itemset diatas tidak terdapat nilai support diatas $30 \%$, maka pembentukan aturan asosiasi akan dibentuk menggunakan 2 itemset.

4) Pembentukan Aturan Asosiasi: Langkah selanjutnya yaitu mencari nilai confidence dari 2 itemset pada Tabel VII. Pada tahap ini, minimal confidence yang diterapkan yaitu 60\%. Rumus yang digunakan adalah sebagai berikut [15].

$$
\frac{\sum \text { transaksiMengandungAdanB }}{\sum \text { transaksiMengandung } A} \times 100 \%
$$

TABEL VII

PEMBENTUKAN ATURAN ASOSIASI

\begin{tabular}{|l|c|}
\hline \multicolumn{1}{|c|}{ Aturan } & Confidence \\
\hline $\begin{array}{l}\text { Jika memproduksi BMW 320, maka juga } \\
\text { memproduksi BMW 328/330 }\end{array}$ & $44,44 \%$ \\
\hline $\begin{array}{l}\text { Jika memproduksi BMW 328/330, maka } \\
\text { juga memproduksi BMW 320 }\end{array}$ & $\mathbf{6 6 , 6 7 \%}$ \\
\hline $\begin{array}{l}\text { Jika memproduksi BMW 320, maka juga } \\
\text { memproduksi BMW 528 }\end{array}$ & $45 \%$ \\
\hline $\begin{array}{l}\text { Jika memproduksi BMW 528, maka juga } \\
\text { mamproduksi BMW 320 }\end{array}$ & $40 \%$ \\
\hline $\begin{array}{l}\text { Jika memproduksi BMW 320, maka juga } \\
\text { memproduksi BMW 7 SERIES }\end{array}$ & $\mathbf{6 6 , 6 7 \%}$ \\
\hline $\begin{array}{l}\text { Jika memproduksi BMW 7 SERIES, maka } \\
\text { juga memproduksi BMW 320 }\end{array}$ & $\mathbf{8 5 , 7 1 4 \%}$ \\
\hline $\begin{array}{l}\text { Jika memproduksi BMW 520, maka juga } \\
\text { memproduksi BMW 528 }\end{array}$ & $\mathbf{6 6 , 6 7 \%}$ \\
\hline $\begin{array}{l}\text { Jika memproduksi BMW 528, maka juga } \\
\text { memproduksi BMW 520 }\end{array}$ & $50 \%$ \\
\hline
\end{tabular}

5) Aturan Asosiasi Final: Aturan asosiasi final ditentukan berdasarkan minimal support dan minimal confidence yang ditentukan. Berdasarkan data yang sesuai dengan minimal support dan minimal confidence yang telah ditentukan, maka dibuat tabel aturan asosiasi final sebagai berikut.

TABEL VIII

ATURAN ASOSIASI FINAL

\begin{tabular}{|l|c|}
\hline \multicolumn{1}{|c|}{ Aturan } & Confidence \\
\hline $\begin{array}{l}\text { Jika memproduksi BMW 320, maka juga } \\
\text { memproduksi BMW 7 SERIES }\end{array}$ & $\mathbf{6 6 , 6 7 \%}$ \\
\hline $\begin{array}{l}\text { Jika memproduksi BMW 7 SERIES, maka } \\
\text { juga memproduksi BMW 320 }\end{array}$ & $\mathbf{8 5 , 7 1 4 \%}$ \\
\hline
\end{tabular}

Berdasarkan Tabel VIII, dapat diketahu produk mobil BMW dengan tipe yang paling banyak diproduksi mobil di PT.Gaya Motor tahun 2018 dapat dilihat pada Gambar 2.

Berdasarkan aturan asosiasi final. Tipe mobil BMW yang paling banyak diproduksi adalah BMW 320 dan BMW 7 Series dan kedua tipe mobil tersebut saling berkaitan. Aturan asosiasi ini dapat digunakan sebagai acuan membuat strategi dan mengelola perusahan dalam meningkatkan efektifitas produksi.

\section{B. Uji Lift Ratio}

Penggunaan lift ratio untuk mengevaluasi kuat tidaknya sebuah aturan asosiasi yang telah dibentuk. Lift Ratio merupakan perbandingan antara confidence sebuah aturan dengan dengan nilai benchmark confidence yang telah didapatkan. Sedangkan Benchmark Confidence merupakan perbandingan antara jumlah semua item yang menjadi consequent terhadap jumlah total transksi yang terjadi [13]. Perhitungan lift ratio yang telah dilakukan dapat dilihat Pada Tabel IX. 


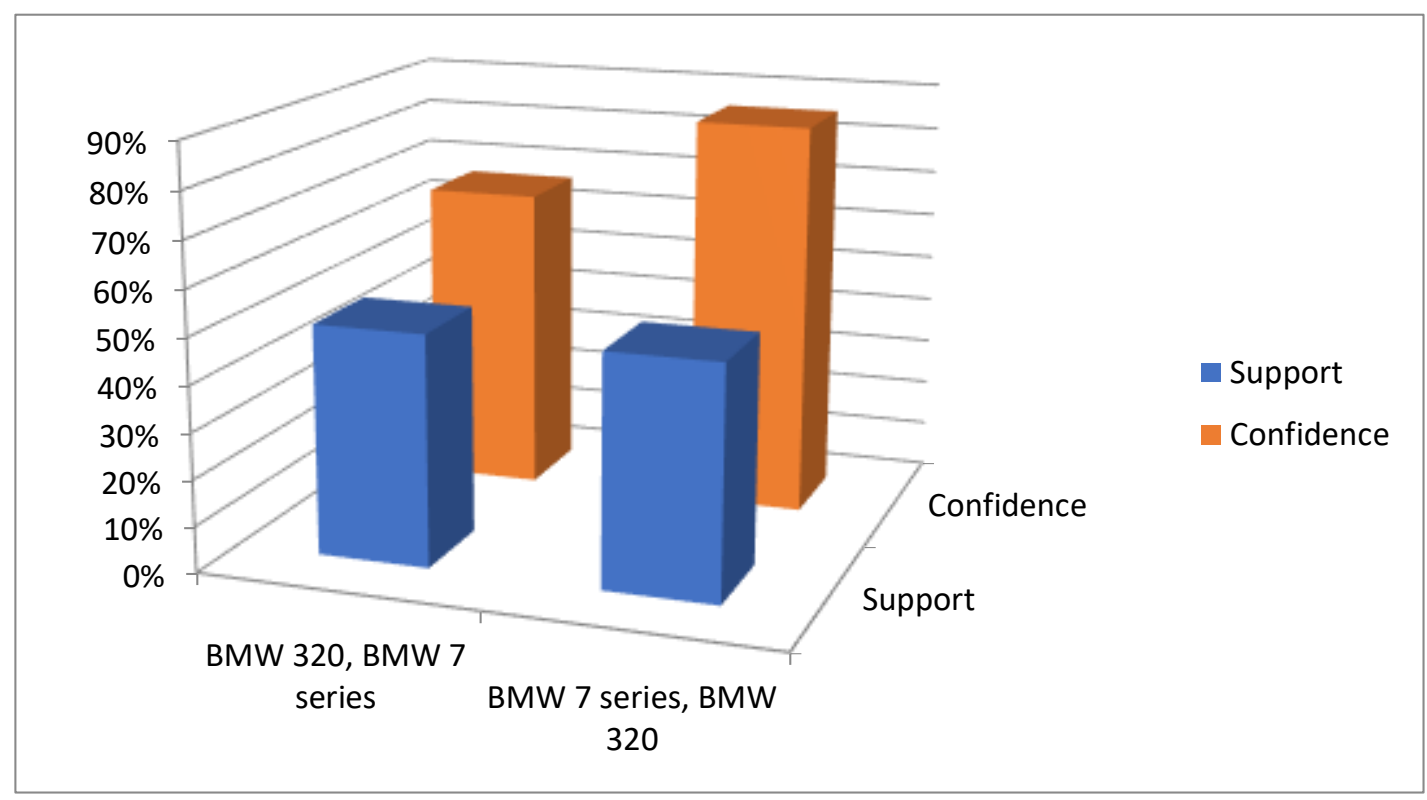

Gambar 2. Grafik Aturan Asosiai Final

TABEL IX

UJI LIFT RATIO

\begin{tabular}{|l|l|l|l|l|l|l|}
\hline \multicolumn{1}{|c|}{ Jika } & \multicolumn{1}{|c|}{ Maka } & \multicolumn{1}{|c|}{ Confidence } & \multicolumn{1}{|c|}{ Support } & \multicolumn{1}{c|}{ Bc } & \multicolumn{1}{c|}{ Lift Ratio } \\
\hline BMW 320 & $\begin{array}{l}\text { BMW } \\
328 / 330\end{array}$ & $44,44 \%$ & $83.33 \%$ & 6 & $6 / 12=0.5$ & $0.44 / 05=0.88$ \\
\hline BMW 328/330 & BMW 320 & $66,67 \%$ & $50 \%$ & 10 & $10 / 12=0.83$ & $0.67 / 0.83=0.807$ \\
\hline BMW 320 & BMW 528 & $45 \%$ & $83.33 \%$ & 8 & $8 / 12=0.67$ & $0.45 / 0.670=0.67$ \\
\hline BMW 528 & BMW 320 & $40 \%$ & $66.67 \%$ & 10 & $10 / 12=0.83$ & $0.4 / 0.83=0.482$ \\
\hline BMW 320 & $\begin{array}{l}\text { BMW } \\
\text { SERIES }\end{array}$ & $\mathbf{6 6 . 6 7 \%}$ & $\mathbf{8 3 . 3 3 \%}$ & $\mathbf{7}$ & $\mathbf{7 / 1 2}=\mathbf{0 . 5 8}$ & $\mathbf{0 . 6 7 / 0 . 5 8 = 1 . 1 5 5}$ \\
\hline BMW 7 SERIES & BMW 320 & $\mathbf{8 5 . 7 1 \%}$ & $\mathbf{5 8 , 3 3 \%}$ & $\mathbf{1 0}$ & $\mathbf{1 0 / 1 2}=\mathbf{0 . 8 3}$ & $\mathbf{0 . 8 5} / \mathbf{0 . 8 3}=\mathbf{1 . 0 2 4}$ \\
\hline BMW 520 & BMW 528 & $66.67 \%$ & $50 \%$ & 8 & 0.67 & $0.67 / 0.67=1$ \\
\hline BMW 528 & BMW 520 & $50 \%$ & $66,67 \%$ & 6 & $6 / 12=0.5$ & $0.5 / 0.5=1$ \\
\hline
\end{tabular}

Hasil uji lift ratio dapat dikatakan kuat dan valid jika nilainya lebih dari 1.00 [13]. Berdasarkan tabel uji lift ratio yang telah dilakukan, terdapat dua rule yang memiliki nilai lift ratio lebih dari 1 (lift ratio $>1$ ). Hal ini menunjukkan dua rule tersebut valid untuk digunakan memprediksi suku cadang mobil BMW berdasarkan tipe.

\section{KESIMPULAN}

Tujuan penelitian ini adalah menerapkan algoritma apriori untuk prediksi suku cadang mobil yang sering muncul. Berdasarkan penelitian yang telah dilakukan, dapat ditarik kesimpulan hasil pengujian yaitu sebagai berikut: a) Tipe mobil BMW yang paling banyak diproduksi tahun 2018 adalah BMW 320 dan BMW 7 Series. Sehingga perusahaan dapat menggunakan hasil ini untuk menentukan strategi terkait pengadaan suku cadang pada tipe mobil tersebut, b) Berdasarkan Uji Lift Ratio yang telah dilakukan, terdapat dua rule yang sangat kuat dan valid untuk digunakan dalam prediksi suku cadang mobil BMW yaitu BMW 320 dan BMW 7 SERIES.

\section{DAFTAR PUSTAKA}

[1] I. Budiman, M. Muliadi, and R. Ramadina, "Penerapan Fungsi Data Mining Klasifikasi untuk Prediksi Masa Studi Mahasiswa Tepat Waktu pada Sistem Informasi Akademik Perguruan Tinggi,” J. Penelit. Ilmu dan Teknol. Komput., vol. 7, no. 1, p. 289138, 2015.

[2] Nada, "Konsep Dasar Data Mining," http://lbi.si.fti.unand.ac.id, 2018. .

[3] N. Pransiska and A. H. Mirza, "Bina Darma Conference on Computer Science PENERAPAN DATA MINING PREDIKSI PENJUALAN BARANG ELEKTRONIK TERLARIS MENGGUNAKAN ALGORITMA NAÏVE BAYES ( Study Kasus: Planet Cash And Credit Cabang Muara Enim ) Bina Darma Conference on Computer Science," Bina Darma Conf. Comput. Sci., pp. 2157-2169, 2016.

[4] Yulia and N. Azwanti, "Data Mining Prediksi Besarnya Penggunaan Listrik Rumah Tangga di Kota Batam Dengan Menggunakan Algoritma C4.5," Semin. Nas. Ilmu Sos. dan Teknol., vol. 1, no. 1, pp. 175-180, 2018.

[5] Sidharta, "Pusat Modifikasi Otomotif BMW di Yogyakarta," Universitas Atma Jaya Yogyakarta, 2009.

[6] Nada, "Konsep Dasar Data Mining," http://lbi.si.fti.unand.ac.id, 2018. .

[7] Ristianingrum and Sulastri, "Implementasi Data Mining Menggunakan Algoritma Apriori," vol. 2, no. 2, pp. 31-39, 2017. 
[8] S. B. A. Saputra, R. Dwiana, W. D. N. Oktaviani, R. D. Isnaeni', T. Astuti, and Nurfaizah, "Implementasi Data Mining Algoritme Apriori Pada Penjualan Suku Cadang Motor Delta Motor," Citisee, pp. 108-113, 2016

[9] D. K. Prabawanti, "Data Mining Prediksi Produksi Spanduk Menggunakan Algoritma Apriori," Universitas Nusantara PGRI Kediri, 2018

[10] A. Salam and M. Sholik, "Implementasi Algoritma Apriori untuk Mencari Asosiasi Barang yang dijual di E-commerce OrderMas," Techno.Com, vol. 17, no. 2, pp. 158-170, 2018.

[11] A. -, F. Marisa, and D. Purnomo, "Penerapan Algoritma Apriori Terhadap Data Penjualan di Toko Gudang BM," JOINTECS (Journal Inf. Technol. Comput. Sci., vol. 1, no. 1, pp. 1-5, 2016

[12] Gakindo.or.id, "GAKINDO Production Data," 2018.

[13] M. Fauzy, R. K. W Saleh, and I. Asror, "Penerapan Metode Association Rule Menggunakan Algoritma Apriori Pada Simulasi Prediksi Hujan Wilayah Kota Bandung," J. Ilm. Teknol. Inf. Terap., vol. 2, No.2, no. 2, pp. 221-227, 2016.

[14] M. Hayaty and W. Dwi, "Penjualan Menggunakan Algoritma Apriori Berbasis Website ( Studi Kasus : Pt . Xyz ),” vol. 3, no. 1, pp. 136-142, 2019 .

[15] D. K. Pane, "Implementasi Data Mining Pada Penjualan Produk Elektronik Dengan Algoritma Apriori ( Studi Kasus: Kreditplus )," Pelita Inform. Budi Darma, vol. valume : I, pp. 2529, 2013. 